\title{
Hypo-Anxious Phenotype of Adolescent Offspring Prenatally Exposed to LPS Is Associated with Reduced mGluR5 Expression in Hippocampus
}

\author{
Dany Arsenault, Aijun Zhu, Chunyu Gong, Kun-Eek Kil, Sreekanth Kura, Ji-Kyung Choi, \\ Anna-Liisa Brownell* \\ Athinoula A. Martinos Center for Biomedical Imaging, Department of Radiology, Massachusetts General \\ Hospital, Harvard Medical School, Charlestown, USA \\ Email: abrownell@partners.org
}

Received 8 January 2014; revised 8 February 2014; accepted 16 February 2014

Copyright (C) 2014 by authors and Scientific Research Publishing Inc.

This work is licensed under the Creative Commons Attribution International License (CC BY). http://creativecommons.org/licenses/by/4.0/

(c) (i) Open Access

\begin{abstract}
Many studies have reported long-term modulation of metabotropic glutamate receptor 5 (mGluR5) by inflammatory processes and a pharmacological modulation of mGluR5 is known to regulate anxiety level. However, it is not known if non-pharmacological modulation of mGluR5 by inflammation impaired the unconditional level of anxiety. In this study, we investigated this relation in LPS prenatal immune challenge $(120 \mu \mathrm{g} / \mathrm{kg}, 3 \mathrm{x}$ i.p. injection in late gestation), a developmental model of neuroinflammation in which some studies have reported hypo-anxious phenotype. Using positron emission tomographic imaging (PET) approaches, we have demonstrated a decrease in the binding potential of $\left.{ }^{[18} \mathrm{F}\right]$ fluoro-5-(2-pyridinylethynyl)benzonitrile( $\left[{ }^{18} \mathrm{~F}\right] \mathrm{FPEB}$, a radioligand for mGluR5) in hippocampus of adolescent offspring prenatally exposed to LPS, without significant change in the binding of [ $\left.{ }^{11} \mathrm{C}\right]$ peripheral benzodiazepine receptor 28 ([11C]PBR28), an inflammatory marker. In addition, dark-light box emergence test revealed a lower level of anxiety in LPSexposed offspring and this behavioural phenotype was associated with the binding potential of [18F]FPEB in hippocampus. These results confirm that neuroinflammation during developmental phase modulates the physiology of mGluR5 and this alteration can be associated with behavioural phenotype related to anxiety. In addition, this study supports a hypotheses that mGluR5 could be used as a diagnostic target in anxiety.
\end{abstract}

\section{Keywords}

Behavior, Anxiety, Immune Response, Inflammation, mGluR5

\footnotetext{
${ }^{*}$ Corresponding author.
} 


\section{Introduction}

In the recent years, metabotropic glutamate receptor subtype 5 (mGluR5) has been a growing subject in research for its beneficial effects in several central and peripheral diseases [1]. Among these disorders, anxiety is one of the most studied [2]. Many preclinical studies have reported an anxiolytic effect of mGluR5 negative modulator [3]-[7] and these observations were supported by a clinical study using fenobam [8] [9]. All of these studies support the idea that mGluR5 is a key player in the regulation of anxiety.

mGluR5 is found on postsynaptic terminals of neurons and microglia [10]. Its signaling is associated to $\mathrm{G}_{\mathrm{q}} / \mathrm{G}_{11}$ and activates phospholipase $\mathrm{C}$, resulting in the hydrolysis of phosphoinositides and generation of inositol 1,4,5-triphosphate (IP3) and diacylglycerol [1]. This typical pathway leads to calcium mobilization and activation of protein kinase C (PKC). This receptor can also modulate G-independent pathway [11]. In vivo, we have previously demonstrated that neuroinflammation generated by a neonatal hippocampal ibotenic acid lesion increases the binding of $\left[{ }^{18} \mathrm{~F}\right]$ fluoro-5-(2-pyridinylethynyl)benzonitrile $\left(\left[{ }^{18} \mathrm{~F}\right] \mathrm{FPEB}\right)$ and up-regulates mRNA expression of mGluR5 in microglia. This response, which is also associated with behavioural impairments (social interactions and memory), can be prevented by treatment with the potent anti-inflammatory compound minocycline [12]. Our results support the idea that neuroinflammation modulates expression of mGluR5 and induces some pathological behavior during development.

Despite these previous demonstrations, it is not clear if an inflammatory-dependent change in the physiology of mGluR5 during development influences the level of anxiety in offspring. Our hypothesis is that inflammation during development modulates mGluR5 expression and induces phenotype of anxiety, and both parameters are related. To investigate it, we have used a model of the prenatal immune challenge with lipopolysaccharide (LPS) in late gestation, in which the inflammatory response is not associated with brain injuries or pharmacological lesions. LPS is a component of the outer membrane of gram negative bacteria and ligand of Toll-like receptors (TLR-4) [13]. When injected to the dam, LPS does not reach the brain of foetuses [14], excluding the possibility that LPS acts directly in this structure. The selected dose $(120 \mu \mathrm{g} / \mathrm{Kg})$ is known to induce brain inflammation in foetus after one injection [15]. The aim of this study was to investigate the impact of LPS induced prenatal inflammatory processes on postnatal mGluR5 expression and anxiety level in adolescent offspring. Inflammation and mGluR5 expression were investigated by imaging approaches whereas dark-light box emergence test was used to quantify the level of anxiety.

\section{Materials and Methods}

\subsection{Animals}

Altogether 30 pregnant C57BL/6 mice were purchased from Charles River Laboratories (Wilmington, Massachusetts), handled in our in-house breeding facility and kept in ventilated cages under standard laboratory conditions. Experimental studies were conducted in 92 pups. The animal studies were approved by the Subcommittee on Research Animals of Massachusetts General Hospital and the Harvard Medical School and carried out by the Guide of the National Institute of Health for the Care and Use of LaboratoryAnimals.

\subsection{Immune Challenges}

Bacterial infections were induced in pregnant mice by intraperitoneal (i.p.) injections of LPS (E. coli serotype 0111:134, $120 \mu \mathrm{g} / \mathrm{kg} / \mathrm{day} ; 0.05 \mathrm{ml} / \mathrm{g}$; Sigma-Aldrich, Missouri, USA). Equivalent volumes $(0.05 \mathrm{ml} / \mathrm{g})$ of sterile saline solution were used for the control treatment. Treatments were administered during late stages of gestation, i.e. between GD15 and GD17 (Figure 1). Note that doses and modes of delivery were chosen based on current literature and selected because of their known impact in inducing neuroinflammation in foetal brain after one injection in the same time windows than in our study [15].

\subsection{Dark-Light Box Emergence Test}

Anxiety-like behavior was assessed using the dark-light box emergence test (Figure 1). The dimensions of the Plexiglas box were $40 \mathrm{~cm} \times 20 \mathrm{~cm} \times 30 \mathrm{~cm}$. The size of each compartment was $20 \mathrm{~cm} \times 20 \mathrm{~cm} \times 30 \mathrm{~cm}$ and the central partition included a door of $4 \mathrm{~cm} \times 4 \mathrm{~cm}$. A mobile roof made of red acetate covered the black compartment. Animals were positioned in the dark compartment. The time spent in each compartment and the number of 


\begin{tabular}{|c|c|c|c|c|}
\hline $\begin{array}{c}\text { Gestational } \\
\text { day (GD) }\end{array}$ & \multicolumn{4}{|c|}{$\begin{array}{l}\text { Postnatal } \\
\text { day }(P n D)\end{array}$} \\
\hline GD15-GD17 & PnD29-30 & PnD33-35 & PnD37-39 & PnD42-44 \\
\hline $\begin{array}{l}\text { daily LPS injection } \\
\text { during } 3 \text { days } \\
\text { (i.p. injection of } \\
120 \mu \mathrm{g} / \mathrm{kg} \text { ) }\end{array}$ & $\begin{array}{l}\text { Grasping } \\
\text { test and } \\
\text { weight } \\
\text { measurement }\end{array}$ & $\begin{array}{l}\text { Dark-light } \\
\text { box } \\
\text { emergence } \\
t \quad \text { test }\end{array}$ & ${ }_{\text {imaging }}^{\left[{ }^{18} \mathrm{~F}\right] \mathrm{FPEB}}$ & $\begin{array}{c}{\left[{ }^{11} \mathrm{C}\right] \mathrm{PBR} 28} \\
\text { imaging }\end{array}$ \\
\hline
\end{tabular}

Figure 1. Time line of experimentations. Pregnant mice (C57BL/6) received daily injections of $120 \mu \mathrm{g} / \mathrm{kg}$ of LPS or an equivalent volumes of saline from GD15 to GD17. Motor function was measured by grasping test between PnD29 and PnD30 whereas dark-light box emergence test was used to quantify the unconditional anxiety level (between PnD33 and PnD35). Two imaging sessions were performed to evaluate the in vivo expression of mGluR5 (PnD37-PnD39) and PBR (PnD42-PnD44). Abbreviations: GD, gestational day; $\left[{ }^{11} \mathrm{C}\right]$ PBR28, peripheral benzodiazepine receptor 28 ; $\left[{ }^{18} \mathrm{~F}\right] \mathrm{FPEB}$, $\left[{ }^{18}\right.$ F]fluoro-5-(2-pyridinylethynyl)benzonitrile; $\mathrm{PnD}$, postnatal day.

box alternation were recorded during a 10-minute (min) session [16] [17].

\subsection{Grasping Test}

Animals were suspended by the forelimbs to a stretched cable of $2 \mathrm{~mm}$ diameter. The time mice remained clinging to the cable was measured to assess muscular tone. Each animal underwent two tests and the best score was kept.

\subsection{PET Ligand and Imaging}

Positron emission tomography imaging (PET) included studies mGluR5 using $\left[{ }^{18} \mathrm{~F}\right] \mathrm{FPEB}$ and studies of inflammatory response using $\left[{ }^{11} \mathrm{C}\right] \mathrm{PBR} 28$ as radiolabeled ligands. For imaging studies animals were anesthetized with isoflurane/oxygen $(1 \%-1.5 \%$ isoflurane at $1 \mathrm{~L} / \mathrm{min}$ oxygen flow). Catheterization of tail vein was done for the administration of the radiolabeled ligands. The animal was adjusted into the scanner (Triumph II, Trifoil Imaging Inc). The level of anesthesia and vital signs were monitored throughout the imaging with the monitoring system of the scanner. For the PET imaging studies, radiolabeled ligand $\left(\left[{ }^{18} \mathrm{~F}\right] \mathrm{FPEB}\right.$ or $\left[{ }^{11} \mathrm{C}\right] \mathrm{PBR} 28,0.2$ $\mathrm{mCi}$, specific activity of $1900 \mathrm{mCi} / \mu \mathrm{mol}$ for $\left[{ }^{18} \mathrm{~F}\right] \mathrm{FPEB}$ and $600-1000 \mathrm{mCi} / \mu \mathrm{mol}$ for $\left.\left[{ }^{11} \mathrm{C}\right] \mathrm{PBR} 28\right)$ was injected into the tail vein and dynamic volumetric data were acquired for $60 \mathrm{~min}$. After the PET data acquisition CT (computed tomography) imaging was done to obtain data for attenuation correction and anatomical information.

PET data was reconstructed with an algorithm based on maximum likelihood estimation using 30 iterations. CT data was reconstructed with a modified Feldkamp algorithm using matrix volumes of $512 \times 512 \times 512$ and pixel size of $170 \mu \mathrm{m}$. The regions of interest including striatum, frontal cortex, hippocampus, hypothalamus, cerebellum, olfactory bulb and whole brain were drawn on all coronal and axial levels using co-registered axial, sagittal, and coronal CT-PET images of the brain. Activity per unit volume, percent activity of injected dose and the ligand concentration were calculated.

Kinetic analysis to determine binding potential of $\left[{ }^{18}\right.$ F]FPEB was done using PMOD3.208 software (PMOD Technologies LTD, Zurich, Switzerland) and reference tissue method with cerebellum as an input function. Since cerebellum does not express mGluR5 or the expression is minimal [18], the input function can be processed from the data obtained from cerebellum in calculating regional maps for binding potential. Concerning $\left[{ }^{11} \mathrm{C}\right]$ PBR28, cerebellum cannot be used as a reference tissue, since inflammation is not brain area specific. The binding for $\left[{ }^{11} \mathrm{C}\right]$ PBR2 28 was determined as percent of the injected activity per $\mathrm{cm}^{3}$. Binding of the ligand to the receptor is an indication of the activity of the receptor since the ligand binds only to membranous receptors.

\subsection{Statistical Analyses}

Values are expressed as mean $+/-$ standard error of the mean (SEM). The normality and equivalence of variances were confirmed in all groups (Figure 2, Figure 3 and Figure 4), accordingly to Kolmogorov-Smirnov and Shapiro-Wilk normality test and the Fisher test (variance analysis). Consequently, both sexes and prenatal 

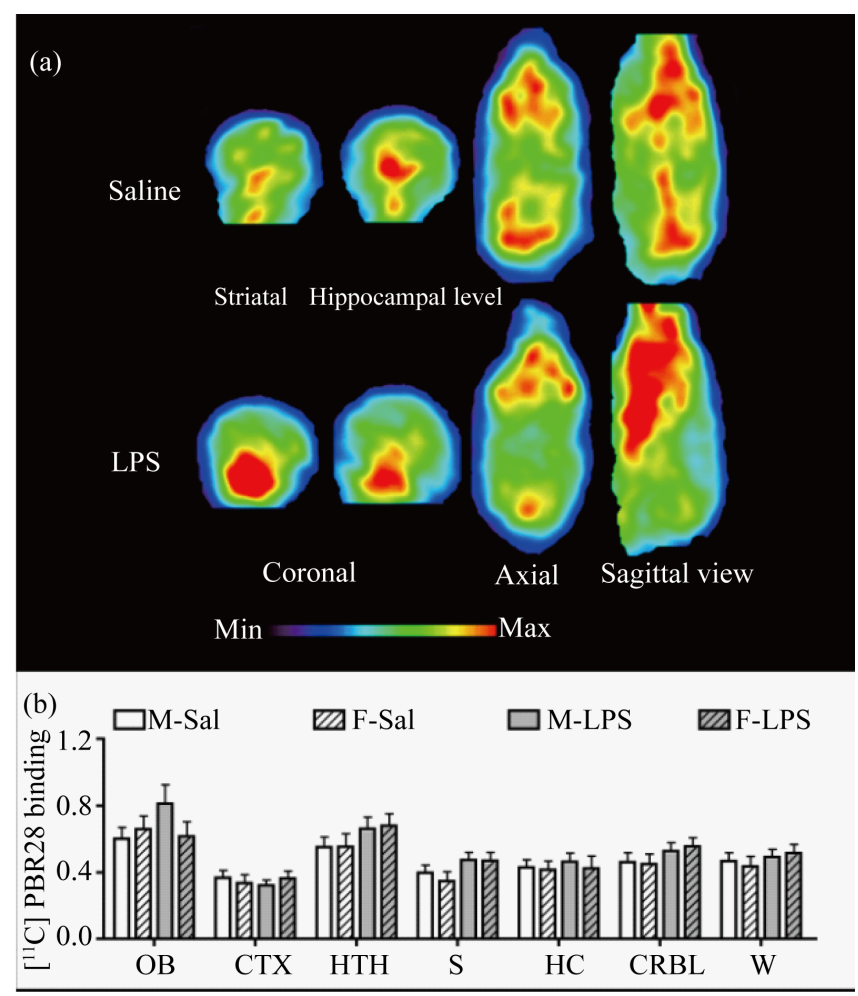

Figure 2. LPS prenatal treatment does not change the binding level of brain $\left[{ }^{11} \mathrm{C}\right] \mathrm{PBR}$. (a) Coronal slices on striatal and hippocampal levels and axial and sagittal slices of the whole brain do not show difference on $\left[{ }^{11} \mathrm{C}\right] \mathrm{PBR} 28$ accumulation in the mouse prenatally exposed to saline or LPS. These images show minimal accumulation in the brain indicating absence of inflammatory processes. The observed accumulation is in the soft tissue areas outside the brain; (b) PET imaging using $\left[{ }^{11} \mathrm{C}\right]$ PBR2 8 targeting activated microglia did not show significant difference between various brain structures. Values are expressed as mean \pm SEM. Statistical analyses were performed using two-way analysis of variance (ANOVA). The number of males and females was $11-13$ and $13-16$ for saline group, whereas it was $15-17$ and $9-13$ for LPS group. Abbreviations: CTX, cortex; CRBL, cerebellum; F-LPS, female-LPS; F-Sal, female-saline; HC, hippocampus; HTH, hypothalamus; M-Sal, male-saline; M-LPS, male-LPS; OB, olfactory bulb; S, striatum; W, whole brain.

treatment were statistically analyzed with two-way ANOVA. Finally, coefficient of determination $\left(\mathrm{r}^{2}\right)$ and the significance of the degree of linear relationship between the various parameters were determined with a regression model. All statistical analyses were performed using JMP (version 9, SAS) and prism (version 4.0, GraphPad Software Inc.) and are presented in Table 1.

\section{Results}

\subsection{Effects of LPS Prenatal Immune Challenge in Brain [11C]PBR85 Binding of Offspring}

LPS treatment did not significantly change $\left[{ }^{11} \mathrm{C}\right] \mathrm{PBR} 28$ binding in hippocampus, cortex, hypothalamus, olfactory bulb striatum or whole brain of adolescent offspring (Figure 2(a) and Figure 2(b)).

\subsection{Modulation of [18F]FPEB Binding Potential in Brain of LPS-Exposed Offspring}

PET imaging revealed a significant reduction of $\left[{ }^{18} \mathrm{~F}\right] \mathrm{FPEB}$ binding potential in hippocampus, but not in the 

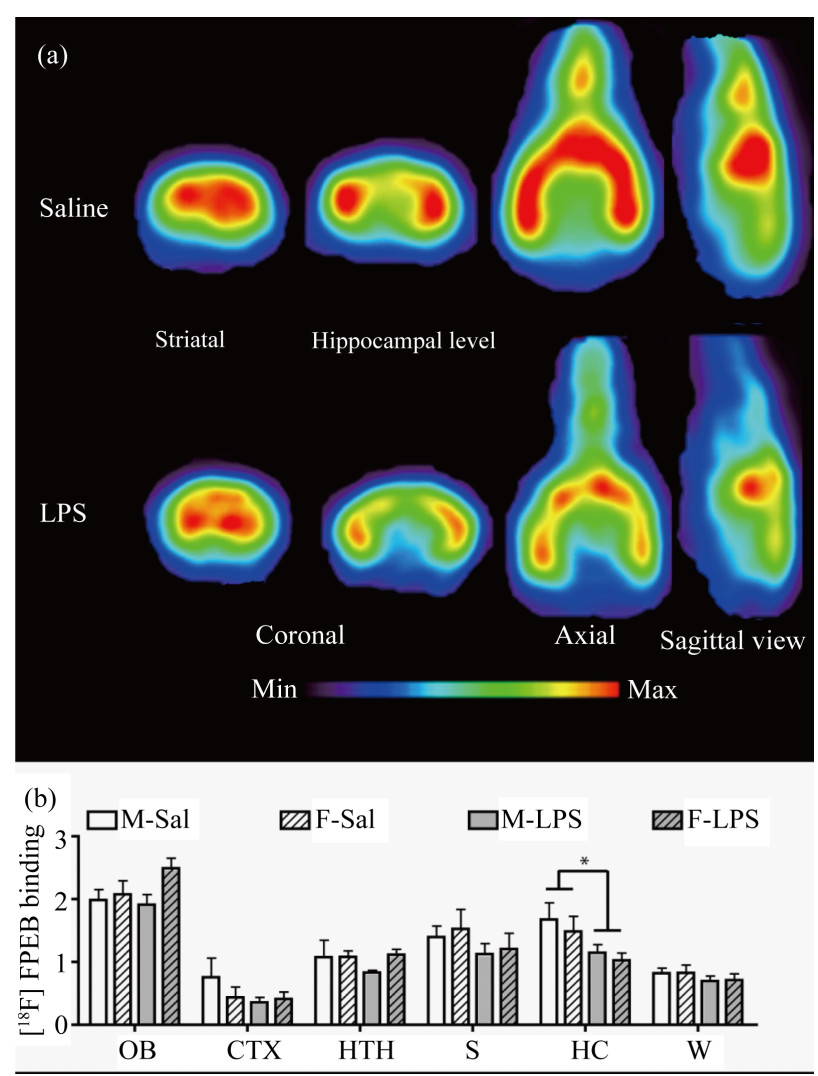

Figure 3. Decreased binding potential of $\left[{ }^{18} \mathrm{~F}\right] \mathrm{FPEB}$ in hippocampus of LPS-exposed offspring. (a) Coronal slices on striatal and hippocampal levels and axial and sagittal slices of the whole brain show significant difference of $\left[{ }^{18} \mathrm{~F}\right]$ FPEB accumulation in the mouse prenatally exposed to saline or LPS. These images show decreased $\left[{ }^{18}\right.$ F]FPEB accumulation especially in the hippocampal area of the LPS exposed mouse indicating significantly decreased mGluR5 expression; (b) PET imaging revealed a decreased binding potential of $\left[{ }^{18} \mathrm{~F}\right]$ FPEB in hippocampus of both males and females prenatally exposed to LPS, without significant changes in other brain structures. Values are expressed as mean \pm SEM. Statistical analyses were performed using two-way analysis of variance (ANOVA). The number of males and females was $14-17$ and $10-11$ for saline group, whereas it was 13 - 15 and 14 - 16 for LPS group. Abbreviations: CTX, cortex; F-LPS, female-LPS; F-Sal, female-saline; $\mathrm{HC}$, hippocampus; HTH, hypothalamus; M-Sal, male-saline; M-LPS, male-LPS; OB, olfactory bulb; S, striatum; W, whole brain. ${ }^{*} \mathrm{p}<0.05$.

cortex, hypothalamus, olfactory bulb striatum or the whole brain (Figure 3(a) and Figure 3(b)).

\subsection{Effects of Prenatal Immune Challenge on Anxiety-Related Behavior and Motor Abilities of Adolescent Offspring}

LPS treatment did not change the weight of animals (Figure 4(a)) and the grasping score (Figure 4(b)) at PnD29-30. In a dark-light emergency test, LPS-exposed offspring spent more time in light box (Figure 4(c)), compared to control group. Further analysis revealed that LPS-exposed offspring did not cross the central part frequently (Figure 4(d)), but spent more time per exploratory events in the light box (Figure 4(d)). Time spent in light box correlated with the binding potential of $\left[{ }^{18} \mathrm{~F}\right]$ FPEB in hippocampus (Figure $4(\mathrm{e})$ ). 


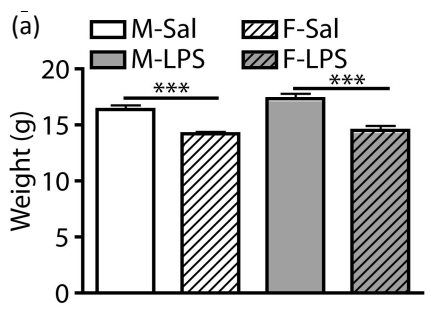

(c)

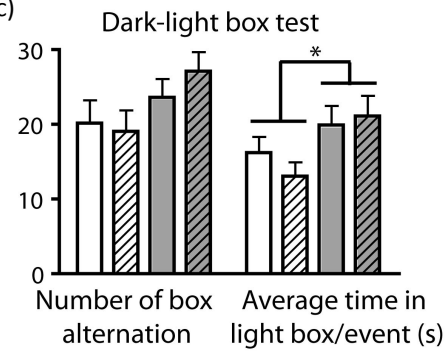

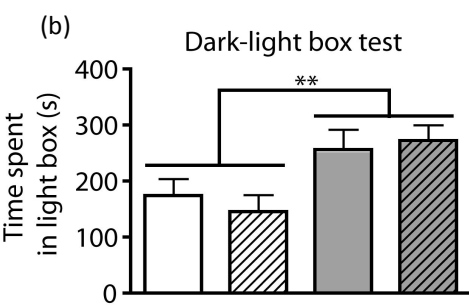

(d)

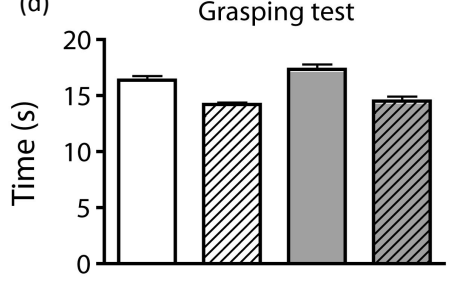

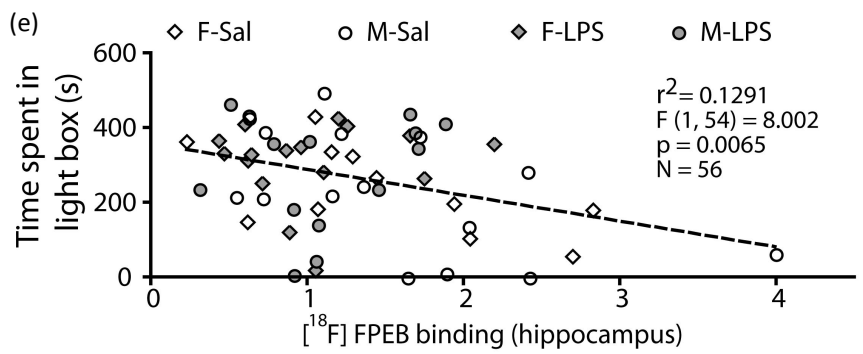

Figure 4. Reduction of unconditional anxiety level in adolescent offspring prenatally exposed to LPS. (a) LPS prenatal exposition did not change the weight of offspring at PnD30; (b) Dark-light box test showed that both males and females exposed to LPS spent more time in the light compartment; (c) Further analysis showed that the number of box alteration did not significantly change in LPS-treated offspring. However, LPS-exposed offspring spent more time per exploratory event in the light box; (d) Grasping ability was similar between all groups; (e) The binding level of $\left[{ }^{18} \mathrm{~F}\right] \mathrm{FPEB}$ in hippocampus correlated negatively with the time spent in the light box. Values are expressed as mean \pm SEM. Statistical analyses were performed using two-way analysis of variance (ANOVA). Correlation was determined by linear regression analysis. Each dot represents a single animal. For panel A to D, the number of males and females was 25 - 29 and 22 - 23 for saline group, whereas it was 20 and $19-20$ for LPS group. Abbreviations: M-Sal, male-saline; F-Sal, female-saline; M-LPS, maleLPS; F-LPS, female-LPS. ${ }^{*} \mathrm{p}<0.05 ;{ }^{* *} \mathrm{p}<0.01 ;{ }^{* * *} \mathrm{p}<0.001$.

\section{Discussion}

\subsection{Prenatal Immune Challenge Did Not Induce Chronic Inflammation in Adolescent Offspring}

In brain, PBR (peripheral benzodiazepine receptor) is expressed in activated glial cells and it is an acceptable target to investigate cerebral inflammation [19]. Targeting this receptor by PET imaging using [ $\left.{ }^{11} \mathrm{C}\right] \mathrm{PBR} 28$, we found that prenatal immune challenge did not induce long-term inflammation in brain of LPS-exposed offspring. In accordance with this result, Cai et al. and Golan et al. have showed that brain inflammation induced by LPS in late gestation occurs during less than 1 day after injection [15] [20], demonstrating that inflammation is transient in foetal brains. Since the new cells produced during development are not activated and do not express PBR, the high neurogenic and gliogenic activity in late gestation is one factor that may explain why inflammation disappears rapidly in foetal brain [21]. PBR is useful to detect acute or chronic brain inflammation, but ex- 
Table 1. Statistical results.

\begin{tabular}{|c|c|c|c|c|c|c|c|c|c|}
\hline \multirow{2}{*}{$\begin{array}{l}\text { Figure } \\
\text { referenced }\end{array}$} & \multirow{2}{*}{ Parameters } & \multirow{2}{*}{ Statistical analysis } & \multirow{2}{*}{$\begin{array}{l}\text { Brain } \\
\text { region }\end{array}$} & \multicolumn{3}{|c|}{ T value } & \multicolumn{3}{|c|}{$\mathrm{p}$ value } \\
\hline & & & & Sex & treat & Inter & Sex & treat & Inter \\
\hline \multirow[t]{6}{*}{ 2B } & {$\left[{ }^{18} \mathrm{~F}\right] \mathrm{FPEB}$} & Two-way ANOVA & OB & $\mathrm{T}=1.87$ & $\mathrm{~T}=0.96$ & $\mathrm{~T}=1.35$ & $\mathrm{p}=0.067$ & $\mathrm{p}=0.344$ & $\mathrm{p}=0.183$ \\
\hline & binding & & CTX & $\mathrm{T}=-0.62$ & $\mathrm{~T}=-1.02$ & $\mathrm{~T}=0.89$ & $\mathrm{p}=0.538$ & $\mathrm{p}=0.315$ & $\mathrm{p}=0.377$ \\
\hline & potential & & HTH & $\mathrm{T}=0.80$ & $\mathrm{~T}=-0.59$ & $\mathrm{~T}=0.79$ & $\mathrm{p}=0.429$ & $\mathrm{p}=0.557$ & $\mathrm{p}=0.435$ \\
\hline & & & $\mathrm{S}$ & $\mathrm{T}=0.45$ & $\mathrm{~T}=-1.25$ & $\mathrm{~T}=-0.11$ & $\mathrm{p}=0.654$ & $\mathrm{p}=0.216$ & $\mathrm{p}=0.909$ \\
\hline & & & $\mathrm{HC}$ & $\mathrm{T}=-0.72$ & $\mathrm{~T}=-2.33$ & $\mathrm{~T}=0.16$ & $\mathrm{p}=0.472$ & $p=0.023$ & $\mathrm{p}=0.873$ \\
\hline & & & $\mathrm{W}$ & $\mathrm{T}=0.09$ & $\mathrm{~T}=-1.22$ & $\mathrm{~T}=0.04$ & $\mathrm{p}=0.926$ & $\mathrm{p}=0.228$ & $\mathrm{p}=0.967$ \\
\hline \multirow[t]{7}{*}{ 3B } & {$\left[{ }^{11} \mathrm{C}\right]$ PBR28 } & Two-way ANOVA & OB & $\mathrm{T}=-0.72$ & $\mathrm{~T}=0.88$ & $\mathrm{~T}=-1.35$ & $\mathrm{p}=0.473$ & $\mathrm{p}=0.380$ & $\mathrm{p}=0.183$ \\
\hline & binding & & CTX & $\mathrm{T}=0.12$ & $\mathrm{~T}=-0.18$ & $\mathrm{~T}=0.8$ & $\mathrm{p}=0.909$ & $\mathrm{p}=0.856$ & $\mathrm{p}=0.427$ \\
\hline & potential & & HTH & $\mathrm{T}=0.14$ & $\mathrm{~T}=1.58$ & $\mathrm{~T}=0.11$ & $\mathrm{p}=0.886$ & $\mathrm{p}=0.120$ & $\mathrm{p}=0.910$ \\
\hline & & & S & $\mathrm{T}=-0.52$ & $\mathrm{~T}=1.88$ & $\mathrm{~T}=0.46$ & $\mathrm{p}=0.606$ & $\mathrm{p}=0.067$ & $\mathrm{p}=0.650$ \\
\hline & & & $\mathrm{HC}$ & $\mathrm{T}=-0.46$ & $\mathrm{~T}=0.36$ & $\mathrm{~T}=-0.20$ & $\mathrm{p}=0.649$ & $\mathrm{p}=0.719$ & $\mathrm{p}=0.845$ \\
\hline & & & CRBL & $\mathrm{T}=0.14$ & $\mathrm{~T}=1.48$ & $\mathrm{~T}=0.43$ & $\mathrm{p}=0.888$ & $\mathrm{p}=0.145$ & $\mathrm{p}=0.736$ \\
\hline & & & $\mathrm{W}$ & $\mathrm{T}=-0.06$ & $\mathrm{~T}=0.93$ & $\mathrm{~T}=0.51$ & $\mathrm{p}=0.950$ & $\mathrm{p}=0.354$ & $\mathrm{p}=0.614$ \\
\hline $4 \mathrm{~A}$ & Weight & Two-way ANOVA & ---- & $\mathrm{T}=-6.23$ & $\mathrm{~T}=1.56$ & $\mathrm{~T}=-0.84$ & $\mathbf{p}<0.001$ & $\mathrm{p}=0.122$ & $\mathrm{p}=0.404$ \\
\hline $4 B$ & $\begin{array}{l}\text { Time spent in } \\
\text { light box }\end{array}$ & Two-way ANOVA & ---- & $\mathrm{T}=-0.19$ & $\mathrm{~T}=3.29$ & $\mathrm{~T}=0.71$ & $\mathrm{p}=0.849$ & $\mathbf{p}=\mathbf{0 . 0 0 1}$ & $\mathrm{p}=0.480$ \\
\hline $4 C$ & Alternation & & ---- & $\mathrm{T}=0.41$ & $\mathrm{~T}=1.98$ & $\mathrm{~T}=0.79$ & $\mathrm{p}=0.680$ & $\mathrm{p}=0.051$ & $\mathrm{p}=0.434$ \\
\hline $4 \mathrm{C}$ & $\begin{array}{c}\text { Average time/ } \\
\text { event }\end{array}$ & Two-way ANOVA & --- & $\mathrm{T}=-0.40$ & $\mathrm{~T}=2.49$ & $\mathrm{~T}=0.92$ & $\mathrm{p}=0.688$ & $\mathbf{p}=\mathbf{0 . 0 1 5}$ & $\mathrm{p}=0.361$ \\
\hline 4D & Grasping time & Two-way ANOVA & --- & $\mathrm{T}=-1.52$ & $\mathrm{~T}=-1.36$ & $\mathrm{~T}=-0.45$ & $\mathrm{p}=0.132$ & $\mathrm{p}=0.176$ & $\mathrm{p}=0.650$ \\
\hline
\end{tabular}

Abbreviations: CTX, cortex; CRBL, cerebellum; F-LPS, female-LPS; F-Sal, female-saline; HC, hippocampus; HTH, hypothalamus; M-Sal, male-saline; M-LPS, male-LPS; OB, olfactory bulb; S, striatum; W, whole brain; $\left[{ }^{11} \mathrm{C}\right] \mathrm{PBR} 28$, peripheral benzodiazepine receptor28; $\left[{ }^{18} \mathrm{~F}\right] \mathrm{FPEB}$, $\left[{ }^{18} \mathrm{~F}\right] \mathrm{flu}-$ oro-5-(2-pyridinylethynyl)benzonitrile.

pression of this receptor cannot inform about the permanent brain abnormalities (network or neuromodulatory impairments) induced by transient inflammatory mechanisms.

\subsection{LPS Prenatal Immune Challenge Reduces [18F]FPEB Binding Potential in Hippocampus}

In vivo, the modulatory effect of inflammation on mGluR5 expression/signaling has been described, especially under pathological conditions such as neuropathic pain [22], amyotrophic lateral sclerosis [23], spinal cord injury [24], epilepsy [25], neonatal hippocampal ibotenic acid lesion [12] and multiple sclerosis [26]. All of these studies reported an increased of mGluR5 in microglia or neurons. However, the functions of this upregulation are not clear. Some animal studies have shown a beneficial anti-inflammatory effect of mGluR5 in a pathological context [24] [27]. Surprisingly, we have observed a lower level of mGluR5 in hippocampus of mice prenatally exposed to LPS, a neuro developmental model of foetal brain inflammation [15]. This difference in the regulation of mGluR5 can be explained by the absence of inflammation in our model. In the studies cited above, all analyzes were made during inflammatory period or in a model of chronic inflammation. However, animals in our study were more consistent with post-inflammatory model, excluding the direct modulation of inflammation on mGluR5. Therefore, the lower level of mGluR5 in hippocampus probably reflects a natural decline in the level of this receptor.

Interestingly, many synaptic and cellular abnormalities were reported in hippocampus of offspring prenatally exposed to LPS during late gestation. For examples, Paintlia et al. have reported a decrease in the immunostaining and mRNA levels of myelin basic protein in hippocampus of LPS-exposed offspring (PnD16 and PnD23, single i.p. injection of $1 \mathrm{mg} / \mathrm{kg}$ at GD18) [28]. In adult offspring, a higher number of hippocampal pyramidal cells with a smaller size (compared to control group) were observed in mice prenatally exposed to LPS (PnD270, single i.p. injection of $120 \mu \mathrm{g} / \mathrm{kg}$ at GD17) [15]. It is also reported that LPS prenatal immune challenge reduces 
dendritic arborisation and dendritic length in CA1 (PnD10, 35 and 60, i.p. injections of $100 \mu \mathrm{g} / \mathrm{kg}$ at GD15 and GD16) [29]. Finally, acceleration of age-dependent drop of long term depression and paired-pulse depression was found in CA1 of LPS-exposed rat offspring (from PnD12-15 to PnD26-50, single i.p. injection of $500 \mu \mathrm{g} / \mathrm{kg}$ at GD19) [30]. These observations demonstrate that LPS exposition in late gestation strongly impairs development of hippocampus at cellular and synaptic levels. The lower level of mGluR5 in LPS-exposed offspring suggests that the physiology of this receptor is sensitive to these cellular and synaptic dysfunctions. The change in mGluR5 cannot be induced by inflammation since we did not detect significant inflammation in brain of offspring prenatally exposed. Taken together, these results support the idea that the physiology of mGluR5 is strongly plastic: its expression is upregulated by inflammation and down regulated in developmental dysfunction in synapses and cells. Our data suggests that mGluR5 is a potent target to image or diagnose network disturbances.

\subsection{Prenatal Exposition to LPS Reduces Anxiety in Adolescent Offspring and This Behavioural Change Is Associated with the Level of Active mGluR5 in Hippocampus}

We have found that the mice exposed prenatally with LPS spent more time in light box. Since the score in the grasping test (motor ability) and the number of box alternations (motivation of animal to explore the box) were not different between each group, the higher time spent in light box of LPS-exposed offspring did not involve motor or motivational aspects. Consequently, this observation reflected a change in unconditional anxiety level. When LPS-treated offspring moved in the light part, they spent more time to explore the light box (the most stressful part of the box) because it was less anxious. In agreement with our results, a lower level of anxiety in offspring prenatally exposed to LPS in late gestation was reported in some studies. Chlodzinska et al. have found that adult mice offspring of LPS-treated dams spent more time in the central part of an open field arena than mice in control group, an indication of low anxiety level (3 months of age, i.p. injection of $300 \mu \mathrm{g} / \mathrm{kg}$ at GD16 and GD17) [31]. In addition, elevated plus maze revealed a lower anxiety level in rat offspring prenatally exposed to LPS (PnD61-80, i.p. injection of $200 \mu \mathrm{g} / \mathrm{kg}$ at GD15 and GD16) [32]. In summary, all of these data supports the idea that inflammatory processes in late gestation impair the development of brain circuits involved in the regulation of anxiety.

Amygdala and hippocampus are two key structures involved in the regulation of anxiety [33]-[36]. An excitotoxic lesion in one of these two cerebral structures produces anxiolytic effects [35]. The regulation of anxiety by hippocampus involves many neurotransmitters [36]. Interestingly, LPS-exposed offspring showed a lower level of mGluR5 expression in one of these two structures: the hippocampus. Our study shows that a physiological down-regulation of mGluR5 expression in a part of this cerebral pathway is sufficient to produce the same anxiolytic effect as the treatment with mGluR5 antagonist [3]-[7]. Taken together, these data suggest that mGluR5 in hippocampus-amygdala network is a key player in the regulation of anxiety.

\section{Conclusion}

This study supports the hypothesis that 1) inflammation modulates the physiology of mGluR5 and 2) this metabotropic glutamate receptor plays a key role in the regulation of anxiety. More precisely, our data show that prenatal exposition to LPS induces down-regulation of mGluR5 expression in hippocampus and decreases the level of unconditioned anxiety, and both factors are correlated. These results confirm the plasticity of mGluR5 and show that physiological change in this receptor can be associated with behavioural phenotype. To conclude, mGluR5 is a new target for diagnostic imaging of behavioural impairments associated with anxiety, in addition to its potential as therapeutic target.

\section{Acknowledgements}

This study was funded by grants from the National Institute of Health 1S10RR029495-01, 1S10RR026666-01 and 1R01MH091684-01. Dany Arsenault was supported by scholarship from Fonds de la Recherche en Santé du Québec (FRSQ).

\section{References}

[1] Niswender, C.M. and Conn, P.J. (2010) Metabotropic Glutamate Receptors: Physiology, Pharmacology, and Disease. 
Annual Review of Pharmacology and Toxicology, 50, 295-322. http://dx.doi.org/10.1146/annurev.pharmtox.011008.145533

[2] Swanson, C.J., Bures, M., Johnson, M.P., et al. (2005) Metabotropic Glutamate Receptors as Novel Targets for Anxiety and Stress Disorders. Nature Reviews Drug Discovery, 4, 131-144. http://dx.doi.org/10.1038/nrd1630

[3] Brodkin, J., Busse, C., Sukoff, S.J. and Varney, M.A. (2002) Anxiolytic-Like Activity of the mGluR5 Antagonist MPEP: A Comparison with Diazepam and Buspirone. Pharmacology Biochemistry and Behavior, 73, 359-366. http://dx.doi.org/10.1016/S0091-3057(02)00828-6

[4] Mikulecka, A. and Mares, P. (2009) Effects of mGluR5 and mGluR1 Antagonists on Anxiety-Like Behavior and Learning in Developing Rats. Behavioural Brain Research, 204, 133-139. http://dx.doi.org/10.1016/j.bbr.2009.05.032

[5] Klodzinska, A., Tatarczynska, E., Chojnacka-Wojcik, E., et al. (2004) Anxiolytic-Like Effects of MTEP, a Potent and Selective mGlu5 Receptor Agonist Does Not Involve GABA(A) Signaling. Neuropharmacology, 47, 342-350. http://dx.doi.org/10.1016/j.neuropharm.2004.04.013

[6] Klodzinska, A., Tatarczynska, E., Chojnacka-Wojcik, E. and Pilc, A. (2000) Anxiolytic-Like Effects of Group I Metabotropic Glutamate Antagonist 2-Methyl-6-(phenylethynyl)-pyridine (MPEP) in Rats. Polish Journal of Pharmacology, 52, 463-466.

[7] Busse, C.S., Brodkin, J., Tattersall, D., et al. (2004) The Behavioral Profile of the Potent and Selective mGlu5 Receptor Antagonist 3-[(2-methyl-1,3-thiazol-4-yl)ethynyl]Pyridine (MTEP) in Rodent Models of Anxiety. Neuropsychopharmacology, 29, 1971-1979. http://dx.doi.org/10.1038/sj.npp.1300540

[8] Pecknold, J.C., McClure, D.J., Appeltauer, L., Wrzesinski, L. and Allan, T. (1982) Treatment of Anxiety Using Fenobam (a Nonbenzodiazepine) in a Double-Blind Standard (Diazepam) Placebo-Controlled Study. Journal of Clinical Psychopharmacology, 2, 129-133. http://dx.doi.org/10.1097/00004714-198204000-00010

[9] Porter, R.H., Jaeschke, G., Spooren, W., et al. (2005) Fenobam: A Clinically Validated Nonbenzodiazepine Anxiolytic Is a Potent, Selective, and Noncompetitive mGlu5 Receptor Antagonist with Inverse Agonist Activity. Journal of Pharmacology and Experimental Therapeutics, 315, 711-721. http://dx.doi.org/10.1124/jpet.105.089839

[10] Hovelso, N., Sotty, F., Montezinho, L.P., et al. (2012) Therapeutic Potential of Metabotropic Glutamate Receptor Modulators. Current Neuropharmacology, 10, 12-48. http://dx.doi.org/10.2174/157015912799362805

[11] Hermans, E. and Challiss, R.A. (2001) Structural, Signalling and Regulatory Properties of the Group I Metabotropic Glutamate Receptors: Prototypic Family C G-Protein-Coupled Receptors. Biochemical Journal, 359, 465-484. http://dx.doi.org/10.1042/0264-6021:3590465

[12] Drouin-Ouellet, J., Brownell, A.L., Saint-Pierre, M., et al. (2011) Neuroinflammation Is Associated with Changes in Glial mGluR5 Expression and the Development of Neonatal Excitotoxic Lesions. Glia, 59, 188-199. http://dx.doi.org/10.1002/glia.21086

[13] Maelfait, J., Vercammen, E., Janssens, S., et al. (2008) Stimulation of Toll-Like Receptor 3 and 4 Induces Interleukin-1beta Maturation by Caspase-8. The Journal of Experimental Medicine, 205, 1967-1973. http://dx.doi.org/10.1084/jem.20071632

[14] Ashdown, H., Dumont, Y., Ng, M., et al. (2006) The Role of Cytokines in Mediating Effects of Prenatal Infection on the Fetus: Implications for Schizophrenia. Mol Psychiatry, 11, 47-55. http://dx.doi.org/10.1038/sj.mp.4001748

[15] Golan, H.M., Lev, V., Hallak, M., Sorokin, Y. and Huleihel, M. (2005) Specific Neurodevelopmental Damage in Mice Offspring Following Maternal Inflammation during Pregnancy. Neuropharmacology, 48, 903-917. http://dx.doi.org/10.1016/j.neuropharm.2004.12.023

[16] Guitton, M.J. and Dudai, Y. (2004) Anxiety-Like State Associates with Taste to Produce Conditioned Taste Aversion. Biological Psychiatry, 56, 901-904. http://dx.doi.org/10.1016/j.biopsych.2004.08.024

[17] Latapy, C., Rioux, V., Guitton, M.J. and Beaulieu, J.M. (2012) Selective Deletion of Forebrain Glycogen Synthase Kinase 3 beta Reveals a Central Role in Serotonin-Sensitive Anxiety and Social Behaviour. Philosophical Transactions of the Royal Society B: Biological Sciences, 367, 2460-2474. http://dx.doi.org/10.1098/rstb.2012.0094

[18] Shigemoto, R., Nomura, S., Ohishi, H., et al. (1993) Immunohistochemical Localization of a Metabotropic Glutamate Receptor, mGluR5, in the Rat Brain. Neuroscience Letters, 163, 53-57. http://dx.doi.org/10.1016/0304-3940(93)90227-C

[19] Venneti, S., Lopresti, B.J. and Wiley, C.A. (2006) The Peripheral Benzodiazepine Receptor (Translocator Protein $18 \mathrm{kDa}$ ) in Microglia: From Pathology to Imaging. Progress in Neurobiology, 80, 308-322. http://dx.doi.org/10.1016/j.pneurobio.2006.10.002

[20] Cai, Z., Pan, Z.L., Pang, Y., Evans, O.B. and Rhodes, P.G. (2000) Cytokine Induction in Fetal Rat Brains and Brain Injury in Neonatal Rats after Maternal Lipopolysaccharide Administration. Pediatric Research, 47, 64-72. http://dx.doi.org/10.1203/00006450-200001000-00013

[21] Panchision, D.M. and McKay, R.D. (2002) The Control of Neural Stem Cells by Morphogenic Signals. Current Opinion 
in Genetics \& Development, 12, 478-487. http://dx.doi.org/10.1016/S0959-437X(02)00329-5

[22] Neugebauer, V. and Carlton, S.M. (2002) Peripheral Metabotropic Glutamate Receptors as Drug Targets for Pain Relief. Expert Opinion on Therapeutic Targets, 6, 349-361. http://dx.doi.org/10.1517/14728222.6.3.349

[23] Aronica, E., Catania, M.V., Geurts, J., Yankaya, B. and Troost, D. (2001) Immunohistochemical Localization of Group I and II Metabotropic Glutamate Receptors in Control and Amyotrophic Lateral Sclerosis Human Spinal Cord: Upregulation in Reactive Astrocytes. Neuroscience, 105, 509-520. http://dx.doi.org/10.1016/S0306-4522(01)00181-6

[24] Byrnes, K.R., Stoica, B., Riccio, A., Pajoohesh-Ganji, A., Loane, D.J. and Faden, A.I. (2009) Activation of Metabotropic Glutamate Receptor 5 Improves Recovery after Spinal Cord Injury in Rodents. Annals of Neurology, 66, 63-74. http://dx.doi.org/10.1002/ana.21673

[25] Aronica, E., van Vliet, E.A., Mayboroda, O.A., Troost, D., Lopes Da Silva, F.H. and Gorter, J.A. (2000) Upregulation of Metabotropic Glutamate Receptor Subtype mGluR3 and mGluR5 in Reactive Astrocytes in a Rat Model of Mesial Temporal Lobe Epilepsy. European Journal of Neuroscience, 12, 2333-2344. http://dx.doi.org/10.1046/j.1460-9568.2000.00131.x

[26] Geurts, J.J., Wolswijk, G., Bo, L., van der Valk, P., Polman, C.H., Troost, D. and Aronica, E. (2003) Altered Expression Patterns of Group I and II Metabotropic Glutamate Receptors in Multiple Sclerosis. Brain, 126, 1755-1766. http://dx.doi.org/10.1093/brain/awg179

[27] Byrnes, K.R., Loane, D.J., Stoica, B.A., Zhang, J. and Faden, A.I. (2012) Delayed mGluR5 Activation Limits Neuroinflammation and Neurodegeneration after Traumatic Brain Injury. Journal of Neuroinflammation, 9, 43. http://dx.doi.org/10.1186/1742-2094-9-43

[28] Paintlia, M.K., Paintlia, A.S., Barbosa, E., Singh, I. and Singh, A.K. (2004) N-Acetylcysteine Prevents Endotoxin-Induced Degeneration of Oligodendrocyte Progenitors and Hypomyelination in Developing Rat Brain. Journal of Neuroscience Research, 78, 347-361. http://dx.doi.org/10.1002/jnr.20261

[29] Baharnoori, M., Brake, W.G. and Srivastava, L.K. (2009) Prenatal Immune Challenge Induces Developmental Changes in the Morphology of Pyramidal Neurons of the Prefrontal Cortex and Hippocampus in Rats. Schizophrenia Research, 107, 99-109. http://dx.doi.org/10.1016/j.schres.2008.10.003

[30] Escobar, M., Crouzin, N., Cavalier, M., Quentin, J., Roussel, J., Lanté, F., Batista-Novais, A.R., Cohen-Solal, C., De Jesus Ferreira, M.C., Guiramand, J., Barbanel, G. and Vignes, M. (2011) Early, Time-Dependent Disturbances of Hippocampal Synaptic Transmission and Plasticity after in Utero Immune Challenge. Biological Psychiatry, 70, 992-999. http://dx.doi.org/10.1016/j.biopsych.2011.01.009

[31] Chlodzinska, N., Gajerska, M., Bartkowska, K., Turlejski, K. and Djavadian, R.L. (2011) Lipopolysaccharide Injected to Pregnant Mice Affects Behavior of Their Offspring in Adulthood. Acta Neurobiologiae Experimentalis, 71, 519527.

[32] Yin, P., Liu, J., Li, Z., Wang, Y.Y., Qiao, N.N., Huang, S.Y., Li, B.M. and Sun, R.P. (2013) Prenatal Immune Challenge in Rats Increases Susceptibility to Seizure-Induced Brain Injury in Adulthood. Brain Research, 1519, 78-86. http://dx.doi.org/10.1016/j.brainres.2013.04.047

[33] Gray, J.A. and McNaughton, N. (2000) The Neuropsychology of Anxiety. 2nd Edition, Oxford University Press, Oxford.

[34] Deacon, R.M., Bannerman, D.M. and Rawlins, J.N. (2002) Anxiolytic Effects of Cytotoxic Hippocampal Lesions in Rats. Behavioral Neuroscience, 116, 494-497. http://dx.doi.org/10.1037/0735-7044.116.3.494

[35] McHugh, S.B., Deacon, R.M., Rawlins, J.N. and Bannerman, D.M. (2004) Amygdala and Ventral Hippocampus Contribute Differentially to Mechanisms of Fear and Anxiety. Behavioral Neuroscience, 118, 63-78. http://dx.doi.org/10.1037/0735-7044.118.1.63

[36] Engin, E. and Treit, D. (2007) The Role of Hippocampus in Anxiety: Intracerebral Infusion Studies. Behavioural Pharmacology, 18, 365-374. http://dx.doi.org/10.1097/FBP.0b013e3282de7929 